\title{
Sciendo
}

DOI: $10.2478 / a a-2021-0016$

\section{Animal symbolism in works of H. P. Lovecraft}

Augustín Sokol, Jozefa Pevčíková

Augustín Sokol is a $\mathrm{PhD}$ student currently studying at the Department of Romance Studies at the Constantine the Philosopher University in Nitra. He previously studied the teaching of English and Biology at Constantine the Philosopher University in Nitra, obtaining a master's degree in 2019. His dissertation thesis is focused on researching reading proficiency in the English language and understanding of English texts among Slovak readers, mainly students learning English as a second language. Previously, he has written articles and research papers related to linguistics, pedagogy, literature and symbolism.

Jozefa Pevčíková is a $\mathrm{PhD}$ student of aesthetics at the Institute of Literary and Artistic Communication at Constantine the Philosopher University in Nitra. Her research includes popular culture, fandom and fan activities, intertextuality, and media studies. Her dissertation thesis aims to map and analyse the influence of H. P. Lovecraft and Cthulhu Mythos on popular culture. The research, based on intertextual theory and media studies, is to be concluded in 2023.

\begin{abstract}
:
Howard Phillips Lovecraft is widely considered to be one of the most influential writers of modern horror fiction and one of the main pioneers of the genre in its current form. One of the less discussed attributes of his work is his use of animal symbolism, despite how common it is, and serves several important functions. We will examine the different forms of animal symbolism in Lovecraft's writing, their use and their respective functions. Our main goal will be to examine how animal symbolism in Lovecraft's work was influenced by cultural and mythological sources and his own opinions towards different creatures and what they represent, in which case we will examine how his knowledge and beliefs may have influenced his depiction of animals. Our focus will be on the depiction of cats, dogs, snakes, aquatic, and amphibious animals as these play a significant role Lovecraftian fiction. We will also examine how animal symbolism connects to the key themes in cosmic horror, such as its negation of anthropocentrism.
\end{abstract}

\section{Introduction}

The writings of H. P. Lovecraft are widely considered to be a specific subgenre of horror referred to as Lovecraftian horror or cosmic horror, often set in the so-called Cthulhu Mythos, which is named after his most famous creation, the cosmic being Cthulhu. One of the core tenets of this sub-genre is the relative insignificance of humanity within the cosmos in comparison to ancient alien races and unworldly supernatural entities. As such, cosmic horror mainly deals 
with existential dread caused by this realization, which often results in the protagonist becoming insane upon witnessing such entities and having their worldview shattered. Lovecraft's literary philosophy of cosmicism shares some traits with nihilism, but instead of claiming that everything is meaningless and there are no universal values at all (as they are all just human constructs), cosmicism subverts humanity's anthropocentric view of itself and claims that the meaning and value of human existence in the vast cosmos is not as great as humanity thinks and that the universe is ultimately indifferent to the fate of all biological life. A controversial aspect of Lovecraftian horror is the author's racial prejudice, which was directed above all towards Jews and people of colour and is often explicitly made clear in his writing. It was his belief that not only are there both greater and lesser creatures than humanity, but also that different ethnic groups are at different stages of development (a philosophy comparable to social Darwinism).

Cosmic horror relies on two main narrative devices to evoke fear in the reader: fear of the unseen (used generally in horror works; e. g. the serpentine entity Yig demonstrating his existence only through a rattling sound, the presence and actions of rattlesnakes, and his transformative curse) and the fear of the unknown (and unknowable/incomprehensible according to HPL, something too alien/strange to our comprehension, whether in sensual, physical or ideological ways). It further features frequent imagery of visceral textures or slime to evoke disgust (Carlin, Allen, 2013).

While the use of animal symbolism is widespread in Lovecraft's writing, we will focus on a few selected examples of his short stories not to expand beyond the scope of this article. The first will be symbolism of sea creatures such as fish and cephalopods, which is particularly prevalent throughout Lovecraftian horror, including the author's most famous works such as Call of Cthulhu, The Shadow Over Innsmouth and Dagon. Other animals that commonly play a significant role in his works are cats and dogs, which can be found in, for example, The Cats of Ulthar, Dream-Quest of Unknown Kadath, The Hound and Pickman's Model. Lastly, we will examine the interesting use of snake symbolism in The Curse of Yig. Apart from determining the origin and inspiration behind the animal symbolism found in these works, we will examine how it is used to convey concepts and ideas characteristic for cosmic horror and Lovecraft's personal views.

Symbolism of cats and dogs (The Cats of Ulthar, Dream-Quest of Unknown Kadath, The Hound, Pickman's Model) 
An animal species particularly cherished by Lovecraft were cats. As a result, their presence in his work is in a positive light, especially in the short story The Cats of Ulthar, in which they are a central plot element, and in the novella Dream-Quest of Unknown Kadath, where they play a significant role. The eponymous town of Ulthar is characterized by a law prohibiting the killing of cats. An unnamed narrator explains the origin of this law, informing the reader about an elderly couple inhabiting Ulthar known for stealing, torturing, and killing cats. The conflict of the story begins when a caravan of nomads passes through the town, one of whom is an orphan boy named Menes who owns a black kitten. When his kitten disappears, he learns about the old couple and assumes their responsibility, after which he recites an incomprehensibly sounding prayer that changes the shape of clouds in the sky. The old couple disappears soon afterwards but a pair of skeletons is later found, with the implication they were devoured by a clowder of cats under the influence of the orphan boy's prayer.

It is observable that Lovecraft wholeheartedly condemned the killing of cats. This attitude is clearly presented in The Cats of Ulthar, in which characters guilty of this get punished and the act itself becomes prohibited by law. As literary critic S. T. Joshi explains, "one can sense Lovecraft's rich satisfaction at the loathsome fate suffered by the evil cat-killing couple" (Joshi, 1996, p. 79). Another author, Katharine M. Rogers, notes that the story is set around the “conventional theme of mysterious feline revenge" (Rogers, 1998, p. 68). The boy's name was likely inspired by the pharaoh Menes who ruled Egypt during the Early Dynastic Period, likely in connection to the significance of cats in Ancient Egyptian culture and mythology, of which Lovecraft was well aware. This is perhaps best demonstrated by the following line from The Cats of Ulthar: "He [the cat] is the soul of antique Aegyptus, and bearer of tales from forgotten cities in Meroë and Ophir. He is the kin of the jungle's lords, and heir to the secrets of hoary and sinister Africa. The Sphinx is his cousin, and he speaks her language; but he is more ancient than the Sphinx, and remembers that which she hath forgotten" (Lovecraft, 2011, p. 88).

Lovecraft's positive view of cats was without a doubt greatly influenced by his personal experiences with the animal, mainly his ownership of a male black cat with the strange name Nigger-Man, which Lovecraft owned during his childhood. In his own words, "for the cat I have entertained a particular respect and affection ever since the earliest days of my infancy" (Lovecraft, 1937). His ownership of Nigger-Man is autobiographically referenced in The Rats in the Walls, where the protagonist owns a cat of the same name. Such autobiographical selfinserts are not atypical for Lovecraftian protagonists ${ }^{1}$. The orphan boy Menes in The Cats of Ulthar can also be considered such an example, since he too owns a black kitten just like Lovecraft in his childhood years. The Cats of Ulthar provides further insight into the writer's 
fascination with cats. "For the cat is cryptic, and close to strange things which men cannot see" (Lovecraft, 2011, p. 88). From this description, it can be gathered that Lovecraft associated cats with mysterious facets of reality largely or entirely unknown to humanity, which are crucial characteristics of Lovecraftian horror. Similar associations can be found throughout culture, since cats, especially black cats, are often connected with mystery and the supernatural and in folklore are frequently depicted as the pets and companions of witches (Rogers, 1998). Some of the qualities which Lovecraft praised in cats are "flawless grace" and "superior selfsufficiency", in which he saw "a symbol of the perfect beauty and bland impersonality of the universe itself" and "silent mystery [where] resides for me all the wonder and fascination of the unknown". He further stated that, in his opinion, cats appeal "to the deepest founts of imagination and cosmic perception in the human mind" and contrasted it with the appeal of dogs, which he considered to stimulate "cheap and facile emotions" (Lovecraft, 1937).

Another of Lovecraft's works, the novella The Dream-Quest of Unknown Kadath, includes cats as well. The main character and Lovecraft's probably most complex alter-ego, Randolph Carter, is in search of the city of Kadath that lies in Dreamlands. During his journey, he is accompanied by a race of intelligent felines (cats from Ulthar, specifically). During Carter's journey from an enchanted forest, he becomes aware that some individuals from the rodent-like ${ }^{2}$ race of zoogs are spying on him. The dogs react to them with frightened barking, but when cats of Ulthar see the zoogs following Carter, they all arch their backs at them - a gesture understood as both defensive and threatening at the same time. The difference in the description of cat and dog behaviour is thus written in favour of brave felines. Carter's second encounter with cats is symbolic in more than one way. Later on in the story, he is captured by maleficent sailors to be sacrificed in a dark ritual and once again cats come to save him. Here, Lovecraft uses one of the symbolic attributes a cat is assigned across cultures, the ability to connect (or even travel between) the physical and the spiritual world and see the unseen. In the story, he turns it into one of Ulthar cats' usual abilities and pastimes:

"It was the midnight yell of the cat, and Carter knew at last that the old village folk were

right when they made low guesses about the cryptical realms which are known only to cats, and to which the elders among cats repair by stealth nocturnally, springing from high housetops. Verily, it is to the moon's dark side that they go...” (Lovecraft, 2011, p. 422) Consequently, the cats defeat a group of Carter's repulsive captors. Lovecraft even names various colours and breeds of the cats, describes their elegance, grace, and that "there hovered over them some trace of that profound and inviolate sanctity which made their goddess great in the temples of Bubastis" (ibid). A noteworthy moment is the description of their return to the 
Dreamlands - on the way to the moon the main character was terrified by "the great black shapelessnesses that lurk and caper and flounder in the abyss" (ibid, p. 423); later, the presence of cats seems to provide him with comfort. When Lovecraft's self-insertion in the story is taken into consideration, it provides an interesting view on his profound adoration of cats.

The third encounter with cats comes when Carter learns that the rodent-like race plans a revenge on the cats of Ulthar. He manages to warn them and Lovecraft provides the reader with a closure of a side storyline - a rare occasion in his work. Not only does he give it a happy ending but puts a lot of attention into the details: Carter once again meets the small black kitten which has grown up in the meantime and their meeting is full of descriptions of cat behaviour - from cats playing with each other to them chasing leaves in the forest to the willingness of the black fellow to accompany Carter on his travels.

Indeed, Lovecraft interestingly uses his thoughts on dogs, cats, and the comparison between the two to express his view of humanity in his essay Cats and Dogs. He argued that people who prefer dogs do so out of a desire for servitude and obedience which stimulates their "primitive feelings" and that they are emotional, superficial, uncritical to the "values of common folklore" and of limited imagination, whereas cat lovers "escape this delusion, repudiate the idea that cringing subservience and sidling companionship to man are supreme merits, and stand free to worship aristocratic independence, self-respect, and individual personality joined to extreme grace and beauty as typified by the cool, lithe, cynical and unconquered lord of the housetops" (Lovecraft, 1937). To Lovecraft, preferring the company of submissive and obedient dogs was a simplistic trait stemming from the innate belief of human superiority, whereas preferring the company of independent, self-sufficient, and rebellious cats is in defiance to such simplistic anthropocentric view.

Despite his preference of cats, dogs play an interesting role in Lovecraft's work as well. There are several works in which dogs are reduced to simple narratological tools: most of the time, they are heralds of bad omens and of the arrival of dark forces (e. g. The Case of Charles Dexter Ward), are either left to die or killed (In the Mountains of Madness, The Curse of Yig). An interesting exception and a more positive role of dogs can be found in The Dunwich Horror when a villainous character of Wilbur Whateley is killed by a dog. However, there are two short stories in which dogs play a significant role - The Hound and Pickman's Model.

The story of The Hound is told by a nameless narrator. He and his partner St. John are treasure hunters and grave robbers. One night they dig a grave in Holland and find a strange amulet decorated with a dog silhouette and decide to add it to their collection. However, upon their return to the US, the duo start hearing weird noises and seeing dark silhouettes behind the 
window. On several occasions, they hear "faint distant baying of some gigantic hound" (Lovecraft, 2011, p. 219). Lovecraft uses this phrase verbatim multiple times, most of them to signalize another bad omen incoming or as a kind of affirmation of the evil supernatural origin of specific events. The thieves soon realize that a demon connected with the amulet is pursuing them - the dark silhouette they have seen, and other clues indicate that the demon's appearance is similar to the carving on the amulet: "[i]t was the oddly conventionalised figure of a crouching winged hound, or sphinx with a semi-canine face..." (ibid, p. 218). This phrase seems rather exceptional in its implied juxtaposition of dogs and sphinx - the mythical creature possessing feline characteristics. It seems even stranger when Lovecraft's opinions on cats and dogs are taken into consideration, as the latter only finds a sworn protestor in the writer. Despite the illusive connection between dogs and the sphinx, a further analysis of the text shows that Lovecraft only used this comparison to outline the basic characteristics of the beast. There is no positive trait of the sphinx or felines to be inscribed to the canine-like demon: "The expression on its features was repellent in the extreme, savouring at once of death, bestiality, and malevolence.” (Lovecraft, 2011, p. 218) The short story can be considered a clear statement from Lovecraft - not only are dogs depicted as heralds of bad omens - or directly as malefactors, with no notion of a positive trait to them; in Lovecraft's vision, they incorporate ugliness, repulsiveness, and the idea of disgust in general both in physical and metaphorical way. Moreover, it is hardly possible to ignore the irony of the story - unlike cat amulets that ought to protect the bearer, bring them luck or otherwise happiness, the dog amulet only brings its owner terror, and, subsequently, doom.

In comparison with The Hound, in his other short story, Pickman's Model, Lovecraft chose a rather different take on dogs and their features. The narrator describes his experience with a friend of his, painter Richard Upton Pickman, who became infamously popular as author of terrifyingly realistic paintings depicting various beasts and perverted gore scenes. During the narrator's visit to Pickman, the painter reveals the truth to him: scenes in his paintings are not fictional but real and inspired by monsters living in abandoned tunnels under Boston. Pickman only photographed or sketched them and then turned these pictures into actual paintings. When the narrator sees some of Pickman's paintings, the first thing that catches his eye is the visual of the depicted beasts. He notices their anthropomorphic physiognomy with "a forward slumping, and a vaguely canine cast" (ibid, p. 385), and even compares them to a hanged witch, "whose dead face held a close kinship to theirs" (p. 385).

It is worth noting that these descriptions reflect what Lovecraft wrote on dogs in the aforementioned essay Cats and Dogs, when comparing the eating habits of these two species - 
he accused dogs of being repulsive in their bestial and insatiate greediness and emphasized their wild (and, thus, inhuman, uncivilized) origin and kinship with wolves and such. Lovecraft then expresses the narrator's disgust upon a painting called "The Lesson", where a group of "nameless dog-like things" (Lovecraft, 2011, p. 385) teaches a small child how to eat like them. However, the most interesting aspect of the text, that can be considered Lovecraft's clear affirmation of dog's unworthiness and repulsiveness, is the way he implies a connotation between Pickman's paintings and works of his favourite artists. There are two connections between fictional and real paintings that stand out.

The first connection is rather minor - upon his arrival to Pickman's atelier, the narrator sees several paintings on which these beasts are "squatting on the chests of sleepers" (p. 385). This description perfectly matches one of the most famous paintings of Henry Fuseli, The Nightmare (1781), in which an impish creature sits on the chest of a sleeping maiden. The dark, threatening tone of the scene is further emphasized by the fact that had probably influenced Lovecraft the most - that the demon sitting on the girl is looking straight at the viewer.

The second connection between fictional and real paintings is represented by a rather detailed description of another Pickman's work, where a beast was devouring a human figure. The joint idea of the horror-evoking scene and Lovecraft's contempt towards dogs resembles another famous painting: Francesco Goya's Saturn Devouring His Son (1819 - 1823). Animal symbolism is included in the description of the monster, which is said to have a "dog face with its pointed ears, bloodshot eyes, flat nose, and drooling lips" (p. 388). Goya's painting is then referenced by the creature's pose: "Its position was a kind of crouch, and as one looked one felt that at any moment it might drop its present prey and seek a juicier morsel." (ibid)

To conclude, Lovecraft's short story Pickman's Model represents an interesting mixture of visual art connotations and animal symbolism which complements a rather simple narrative. In these terms, canine attributes that are used here are not only fictional and imaginative, but find support in real works of art. However, Lovecraft does not change his judgement of dogs and keeps inscribing them with negative characteristics and symbolic traits. In contrast with the mythological and spiritual approach he chose in The Hound, here, canine features represent a significant addition to motifs of perverted violence and gore.

\section{Symbolism of snakes (The Curse of Yig)}

One of the most ubiquitous and diverse kinds of animal symbolism, which is the symbolism of snakes, can be found in The Curse of Yig. This short story was written by Lovecraft in collaboration with another American author, Zealia Bishop, in 1929. The titular character, Yig, 
is a serpentine creature referred to as "The Father of Serpents" and is largely inspired by snakelike deities like the feathered serpent Quetzalcoatl from Mezo-American mythologies. This connection is even explicitly mentioned in the story and is further emphasized by the fact that Yig is worshipped by various tribes of Native Americans. The main conflict of the story stems from a woman killing a nest of rattlesnakes, which, as her terrified husband claims, is the cause of Yig's curse. From that moment, the couple believes they are being pursued by Yig.

It should also be noted that the husband himself, while suffering from ophidiophobia, doesn't get killed by Yig, but by his own wife after she mistakes him for Yig. However, the woman herself becomes affected by the serpentine entity, as she eventually gives birth to a strange, disfigured creature that appears to be a snake-human hybrid. This serves as evidence of Yig's involvement. The narrator who investigates the bizarre event comes across the hybrid creature but never across Yig himself and is only aware of him thanks to archives about the case. Lovecraft often used this indirect style of storytelling in his later works (the most famous example being Call of Cthulhu, as Cthulhu himself is never confronted by the narrator of the story but is mentioned and described in archives and accounts from other people). This ensures Yig's menacing presence without him ever appearing directly to the narrator, which embodies the fear of the unseen characteristic of many Lovecraftian entities and cosmic horror overall. While Yig certainly is an antagonistic force and a menacing presence within The Curse of Yig, he doesn't appear to be extremely malicious, since his acts of violence are said to be a reaction to the killing of snakes. From a snake's perspective, Yig is a protective figure, and his acts are (arguably) justified. A connection could be drawn between his behaviour and nature of real snakes, since most fatal encounters with snakes are defensive rather than the result of an active desire to seek out and attack humans. It should also be remembered that Yig never directly kills anyone in the story, although it can be argued that the woman's fate is worse than death, since she accidently killed her husband, was sent to an insane asylum afterwards and gave birth to a grotesque inhuman entity.

In this short story, Yig can be understood as a mythological being, which is quite unusual for Lovecraft's work. Lovecraft's most popular creations (e. g. Cthulhu, Azathoth, Yog-Sothoth etc.) are considered part of mythology only by name - they lack the mythological relationship with humans, they do not intervene in human activities, they do not serve as moral cursors, and they do not represent Good or Evil per se (they are only perceived as such by humans). Although Lovecraft included Yig into his "pantheon", the serpentine creature's relationship towards humankind is not indifferent or non-existent, but rather tolerant. Its behaviour towards people is active and highly dependent on the human approach towards snakes (its children and 
protégés). If the animals (as well as Yig himself) are treated with respect and care, Yig remains tolerant (rewarding, even) - if snakes are harmed or killed, the deity grows revengeful and brings curses upon the wrongdoers. Even the Native Americans who worship Yig seem to fear him to a degree, as they try to please him with rituals and offerings. It is said about Yig that "in the autumn he became abnormally ravenous, and had to be driven away by means of suitable rites" (The Curse of Yig, 1929).

On the other hand, the major subject matter of The Curse of Yig is ophidiophobia and the physical sensations connected with fear and disgust of snakes. This is explicitly clear even in the opening lines by the narrator: "In 1925 I went into Oklahoma looking for snake lore, and I came out with a fear of snakes that will last me the rest of my life" (The Curse of Yig, 1929). Fear of snakes (or, in this case, the disgust) was also the motive for the wife to exterminate a nest of rattlesnakes. Overall, the theme of a snake-like entity that is both feared and worshipped is quite representative of how snakes have been viewed by humanity throughout history and their mark on our mythology, being a source of both terror and fascination that has left a significant impact on many different cultures. Yig seems to embody the conflicting effect which snakes have had on humanity since the dawn of time that results in their frequent depiction in religion, myths, and legends, which ranges from godly worship to demonic condemnation.

Further in the story, Lovecraft turns from Mesoamerican myths to Christian mythology, in which snakes are understood inter alia as of Evil and as companions of witches. This is supported by Lovecraft's choice of date - the climax of the story comes during the night after a party that was held on Halloween, at the time of "the dread Witch-Sabbath of the primal preAryans" (The Curse of Yig, 1929).

Concerning the feeling of disgust, the description of sensual stimuli (perceived mostly by smell, sight, and touch) has proven specifically effective when it comes to arousing the reader's sense of horror and disgust. This idea is described by Jens Malte Fischer in his essay on Lovecraftian horror (in Lovecraft, 2012). Fischer further develops Freudian psychoanalytical theory that the human feeling of loathing is connected above all to insects, rats and reptiles as well as to slithery, swarming, or romping movement, the movement of a quivering mass and connection with decay etc. (ibid).

Lovecraft developed Bishop's original idea of a rhumba of rattlesnakes threatening a young pair and added sensational descriptions to induce disgust in his reader. These descriptions include those connected with sight (the slithery movement of snakes, the swarming movement in the nest and then on the floor of Davises' cabin) and those connected with smell and sound 
(Audrey's imaginary pictures of decaying bodies include "putrid pop of cleft skin" and "that obscene stench").

In the sense of the short story, Lovecraft's ideas concerning snake mythology and presence, although focusing mainly on the negative notions that are supposed to evoke horror, are strictly tied with the ambivalent position of snakes in human history and culture.

\section{Symbolism of marine creatures (The Call of Cthulhu, Dagon, The Shadow Over Innsmouth)}

Fish and other aquatic creatures play a significant role in Lovecraft's fiction. Most notable of these are: Dagon (written 1917), Lovecraft's first story to introduce a Cthulhu Mythos element; The Call of Cthulhu (w. 1926), the most popular Mythos story, and the novella The Shadow Over Innsmouth (w. 1931), Lovecraft's only work published in book form during his life.

It is possible to identify two basic approaches to the ichtyic, amphibian or aquatic symbolism in Lovecraft's work. First, the typical attributes of these animals (fish, octopuses, frogs etc.) are assigned to the fictional hybrids from Lovecraft's work and create a direct link to the ocean as their natural environment. Second, the animals are often depicted as being of abomination, putridity, and disgust, and are connected with descriptions of unpleasant sensory experience.

Lovecraft uses ichtyic symbolism in connection with descriptions of the narrator's discomfort, disgust, and sensual unpleasantness. This connection probably stems from Lovecraft's personal attitude towards sea life. As Jens Malte Fischer claims in his essay Produktiver Ekel (Czech translation in Lovecraft, 2012), the writer refused to eat fish and other similar foods and found fish scent especially repulsive. However, Fischer points out another reason for fish presence in Lovecraft's work - its connection to the sensory experience is based on the phenomenological nature of disgust and its correlated meanings. It was further examined in Aurel Kolnai's essay On Disgust (2004). According to Kolnai, "[ $\mathrm{t}]$ he main carriers of the sensation of disgust are the olfactory, visual and tactile senses" (p. 48), with the note that smell is directly connected with the sense of taste.

Kolnai named nine types of disgusting elements: the process of putrefaction, dissolution, or decomposition; excrements and bodily secretions, dirt; then, too, disgusting animals, especially insects when they appear in swarms or animals that crawl (vermin, invertebrates); foods in specific conditions; human bodies in our proximity; exaggerated fertility (either of particular animals or plants); disease and deformity (and the notion of "life in the wrong place" (ibid, p. $62)$ ). 
In Dagon, the two approaches - symbolic and phenomenological - are closely intertwined, as both Lovecraft's antipathy towards sea animals and the description of sensory experience of disgust are present. At first, the description of unpleasant (resp. disgusting) sensory experience is connected with narrator's environment, as it is stated that the man found himself stuck in "a slimy expanse of hellish black mire" (Lovecraft, 2011, p. 23). The negative symbolic connection between fish and unpleasantness is created further in the story, when the strange land is explored and the narrator remarks that " $[\mathrm{t}]$ he region was putrid with the carcasses of decaying fish..." (ibid., p. 24) and that "[t]he odour of the fish was maddening" (ibid.).

The negative connotation of fish and sea creatures is later supported by a mythological element. When the main character discovers an ancient monolith, he describes it as decorated with "aquatic symbols such as fishes, eels, octopi, crustaceans, molluscs, whales, and the like" (ibid., p. 25). It is worth pointing out that all of these creatures possess characteristics that match Kolnai's typology of disgust - many of them are slimy to the touch, move by crawling or their movement or grouped life alludes swarming. Even the element of bodily deformation is present, as Lovecraft hints on existence of hybrid inhuman creatures with "webbed hands and feet, shockingly wide and flabby lips, glassy, bulging eyes, and other features less pleasant to recall" (ibid., p. 26). However, the final point in connection between fish and disgust is made through the mythological creature, later named Dagon, which is seen emerging from the dark waters and described having scaly arms.

Klinger (2014) emphasizes Lovecraft's knowledge of Hebrew mythology and Milton's Paradise Lost, both of which feature a sea deity called Dagon that was sometimes depicted or described as having fish-like characteristics. Despite the fact that Dagon (resp. Dagan) is now considered a god of prosperity and wheat, it is possible that Lovecraft really drew his inspiration from these sources - the association of the Dagon deity with sea and fish was only disproved after he wrote his short story (e. g. Singer, 1992). The Dagon-creature's fictional existence does not only connect the symbolic and the sensory in terms of disgust, but also strengthens the connection between fish (resp. sea life) and its negative impact on humans - whether in physical (sensory) or psychical (mind-harming) ways. Thus, as can be seen in other Lovecraft's stories after Dagon, there is no positive symbolism connected with fish and other similar animals.

Aquatic animals are treated the same way in The Call of Cthulhu, in which the narrator, Francis Wayland Thurston, slowly uncovers truth about the mythical creature dwelling in the depths of the Pacific Ocean. At the beginning of the story, the titular creature is described as having "an octopus-like head whose face was a mass of feelers, a scaly, rubbery-looking body [...] of a somewhat bloated corpulence" (Lovecraft, 2011, p. 362). As the story continues, Lovecraft adds 
more characteristics to the description of Cthulhu: it is perceived by Johansen as "the green, sticky spawn of the stars" (ibid., p. 377), and when the sailor hits the monster with a ship, there is "a bursting as of an exploding bladder, a slushy nastiness as of a cloven sunfish, a stench as of a thousand opened graves..." (ibid., p. 378).

In the case of this short story, the negative connotation of aquatic life spreads to its environment as well. Seas and oceans seem to gain the meaning of a mysterious, impenetrable environment, of something inherently malevolent that covers (therefore, protects) all the unspeakable or indescribable horrors that the human race should be afraid of. In Lovecraft's stories, it is not only that the unknown horrors emerge from the ocean's depths, but also the inability of humans to completely explore and understand it $^{3}$. It could be argued that he tries to evoke a feeling of fear similar to that which individuals suffering from thalassophobia experience in deep waters. The description of R'lyeh supports this claim: “The great stone city R'lyeh, with its monoliths and sepulchres, had sunk beneath the waves; and the deep waters, full of the one primal mystery through which not even thought can pass, had cut off the spectral intercourse." (ibid., p. 368). The idea of the mass of water that hides horrors in itself explains "why the sound of the water against the vessel's sides became so unendurable" (p. 375) to the narrator. As he adds: "[w]hen I think of the extent of all that may be brooding down there I almost wish to kill myself forthwith" (ibid.) and: "Loathsomeness waits and dreams in the deep..." (Lovecraft, 2011, p. 379).

As can be seen, Lovecraft gradually strengthened the symbolic connection between aquatic animals and negative connotations such as disgust, thalassophobia and the fear of doom. All of these elements are then present in a unified form in his novella The Shadow Over Innsmouth. Narrator's journey to the coastal Innsmouth is already foreshadowing its malevolent nature, as "[t]he smell of the sea took on ominous implications" (Lovecraft, 2011, p. 817), and after his arrival he realizes that "[p] ervading everything was the most nauseous fishy odour imaginable" (ibid., p. 818). The same implication is presented in the description of the inhabitants of the town, who have narrow heads, flat noses, bulgy eyes and strangely deformed skin on their necks (Lovecraft, 2011).

It should be noted that the population of Innsmouth is a product of interbreeding between the fish-like Deep Ones and the original human inhabitants of Innsmouth. These hybrids are born looking as ordinary people but gradually transform into pure Deep Ones as they age and return to the ocean once their transformation is complete. Crossbreeding of people and non-human entities was used by Lovecraft to express his opposition to marriage and conception between different races, a view stemming from the author's racist views. While such an opinion is 
understandably controversial, Lovecraft truly was openly racist and he frequently expressed it throughout his writing. Therefore, this fact cannot be ignored while analysing his works if we are to truly denote their intended meaning.

There are several parts of the text where the inhabitants, just as well as the sea creatures, are described - these descriptions are similar to those in Dagon and The Call of Cthulhu and will not be repeated here. Similarly, the sea is once again described as the place from which this evil originated - "that cursed place of all wickedness whar the deep water starts. Gate o' hell..." (Lovecraft, 2011, p. 827). In addition to that, Lovecraft adds another creature from an existing mythology, that bears negative connotations with sea life - "Mother Hydra" (ibid., p. 834), which is stated as one of parents of the fish-like creatures from the depths, with "Father Dagon" (ibid.) being the other.

The end of the story serves as closure to a symbolic circle. What has started with simple descriptions of sensory disgust, had continued through its connection to fish and other aquatic animals and the evocation of fear of the deep sea (thalassophobia), and comes to an end with the narrator slowly turning into another fish-hybrid and descending into the depths of the ocean to live with his relatives and wait for Lovecraft's godly creatures to rise again.

\section{Conclusion}

Typically, animal symbolism in H. P. Lovecraft's stories serves to evoke feelings of fear, disgust and hopelessness, which is why it often centres around animals that are widely feared and loathed, such as snakes in The Curse of Yig, or creatures often associated with slime, wetness and the vast and mysterious sea. Indeed, the imagery of oceans and sea creatures is particularly widespread throughout his writing and is the key motif of some of his most famous works, such as Call of Cthulhu, Dagon and The Shadow Over Innsmouth. This is largely due to connotations of the sea to mystery and unseen horrors unexplored by humanity, emphasizing the fear of the unknown and the fear of the unseen, both of which are crucial to cosmic horror. The author's racial prejudice that often appears in his work is expressed through hybrids of humans and inhuman animalistic creatures in The Shadow Over Innsmouth and The Curse of Yig, which serves as his critique of racemixing.

On the contrary, cats are depicted universally in a positive light, such as in The Cats of Ulthar where harming cats is severely punished and in Dream-Quest of Unknown Kadath, in which cats help the protagonist (who is largely a self-insert of Lovecraft himself) and even saving his life on a few occasions. Lovecraft viewed cats as sophisticated, intelligent and having a connection to supernatural elements of reality that are beyond human comprehension. As such, 
they are one of the few animals in his stories to carry positive connotations rather than serving to make the reader anxious, uneasy or disgusted. This contrasts greatly with Lovecraft's depiction of dogs, which are shown in a generally negative light due to his own unfavourable feelings towards in the animals. Often they are depicted as an omen of death and destruction, like in The Hound. Furthermore, the subterranean man-eating ghouls from Pickman's Model have canine characteristics.

Deconstruction of anthropocentrism, which is another central theme of cosmic horror, is achieved mainly through cosmic beings that are far superior to humanity. As mentioned, many of these, such as Cthulhu or Dagon, are depicted with characteristics of sea creatures like octopi and fish, while others have characteristics of different animals, such as the serpentine Yig. Interestingly, Lovecraft expressed his criticism of human values in Cats and Dogs through a juxtaposition of the two animals, comparing the self-reliant and independent cats to the submissive and servile dogs, praising the former and chastising the latter.

Lovecraft frequently took inspiration from mythology and often made direct references to it. Such examples are Yig who is associated with Mesoamerican snake-like deities and oceanic beings like Dagon and Mother Hydra taking inspiration mythological beings connected to the sea. Ancient Egyptian mythology in particular influenced Lovecraft's work significantly and references to it are often made in connection to cats. Lovecraft's personal preferences and opinions are obvious in his approach to both cats and dogs and are frequently reflected throughout his writing, often quite autobiographically through protagonists who share his views, such as his liking of cats and dislike of dogs.

\section{Endnotes:}

${ }^{1}$ Many of Lovecraft's protagonists shared numerous attributes with him, being mostly well-educated white men (preferably of Anglo-Saxon heritage) sharing a number of Lovecraft's interests and habits. An example of this is Robert Olmstead, the narrator of The Shadow Over Innsmouth, who even shares Lovecraft's eating habits, often surviving on canned vegetable soup throughout the day.

${ }^{2}$ The original description of zoogs is rather simple - Lovecraft states that "one sees their weird eyes long before one can discern their small, slippery brown outlines" (Lovecraft, 2011, p. 411). Their nowadays generally accepted rat-like appearance was only established (and gradually accepted by wider audience) by Chaosium.

${ }^{3}$ If seen as the earthly counterpart of space, it can be understood as one of the representations of Lovecraft's literary philosophy of cosmicism.

\section{Acknowledgement:}

This work was supported by the Slovak Research and Development Agency under the contract no. APVV-17-0071.

\section{Works cited:}


Carlin, G., Allen, N., 2013.Slime and Western Man: H. P. Lovecraft in the Time of Modernism. In: Simmons, D., New Critical Essays on H. P. Lovecraft. Palgrave Macmillan, New York, pp. 73-90.

Klinger, L. S., 2014. The New Annotated H. P. Lovecraft. New York: Liverlight, 2014.

Lovecraft, H. P., 2011. H.P. Lovecraft (Barnes \& Noble Collectible Classics: Omnibus Edition): The Complete Fiction. $2^{\text {nd }}$ ed. New York: Barnes and Noble, 2011.

Joshi, S. T., 1996. A Subtler Magick: The Writings and Philosophy of H.P. Lovecraft. New Jersey: Wildside Press, $3^{\text {rd }}$ ed..

Rogers, K. M. 1998. The Cat and the Human Imagination: Feline Images from Bast to Garfield. The University of Michigan Press.

Lovecraft, H. P., 1937. Cats And Dogs. [online]. 1937, Leaves, 1 (Summer 1937), pp. 25-34 [cit. 2021-09-06]. Available at: https://www.hplovecraft.com/writings/texts/essays/cd.aspx Lovecraft, H. P., 1929. The Curse of Yig. [online]. 1929, vol. 14, no. 5 [cit. 2021-09-06]. Available at: https://www.hplovecraft.com/writings/texts/fiction/cy.aspx

Lovecraft, H. P., 2012. Spisy 3/II: Volání Cthulhu. Praha: Plus, 2012, p. 328.

Singer, I., 1992., Towards the image of Dagon, the god of the Philistines. In: Syria. Vol. 69, nr. 3-4, 1992, pp. $431-450$.

Kolnai, A., 2004. On Disgust. Chicago: Open Court, 2004.

Augustín Sokol

Faculty of Arts

Constantine the Philosopher University in Nitra

Slovakia

augustin.sokol@ukf.sk

Jozefa Pevčiková

Faculty of Arts

Constantine the Philosopher University in Nitra

Slovakia

jozefa.pevcikova@ukf.sk 